\title{
APPLYING A MIXED COAGULATION AGENT - CHITOSAN-POLYALUMINUM CHLORIDE - FOR THE TREATMENT OF WASTEWATER WITH PETROLEUM HYDROCARBONS
}

Smaranda Masu

INCD-ECOIND, Branch of Timisoara, 300004, 1 Regina Maria Square, Timisoara, email smarandamasu@yahoo.com, Romania

\begin{abstract}
The study assessed the efficiency of the coagulation process of wastewater with petroleum hydrocarbons content, by using mixed coagulants derivatives of polyaluminum chloride, (characterized by the molar ratio $\mathrm{OH}: \mathrm{Al}=2.4$ ), mixed with various amounts of chitosan. Systematic study was conducted to define the mixed coagulant, respectively chitosan:polyaluminum chloride product, by relating its two components, within the context of optimal dosage used in the coagulation process, determined experimentally by the Jar Test method. The coagulation efficiency was examined by conventional parameters: $\mathrm{pH}$, turbidity, COD, TOC, TPH (Total Petroleum Hydrocarbons) and the unconventional parameter - absorbance at wavelength $254 \mathrm{~nm}, A$ 254. Coagulation performance determined with the mixed chitosan - polyaluminum chloride coagulant was reported to the results obtained by coagulating with polyaluminum chloride in the absence of chitosan. The results suggest that the use of mixed chitosan - polyaluminum chloride coagulation agent, prepared at a ratio of chitosan : $\mathrm{Al}=0.6$, can significantly reduce the optimum dose of $\mathrm{Al}$, more than $50 \%$, and obtain treated samples with the same characteristics as the samples treated with optimal doses of polyaluminum chloride
\end{abstract}

Keywords: chitosan, coagulation, polyaluminum chloride, total petroleum hydrocarbons, wastewater

\section{Introduction}

In the present study was assessed the removal efficiency of total petroleum hydrocarbon (TPH) from wastewater through a coagulation / adsorption stage using a mixed coagulating agent chitosan - poly aluminum chloride at a ratio chitosan: $\mathrm{Al}=0.3$ and 0.6 , compared with process efficiencies done with $\mathrm{PAC}$ treatment. The competitiveness of the introduction of a spectrophotometric measurement parameter for a rapid organic load of the raw and treated water, A254, absorbance at $254 \mathrm{~nm}$ wavelength, was assessed. Chitosan contains high amounts of compounds with hydroxyl and amine functional groups. Chitosan has great power to neutralize the charges and coagulate and also to absorb the pollutants, and is cheaper and more effective than other materials [1-3]. Currently, experimental studies are incomplete regarding the use of these materials for the removal of petroleum compounds from wastewater [3]. Wastes from shells and fish debris resulting in large quantities in various countries such as China, Thailand and Japan are considered precursors to obtain coagulating and adsorption agents, i.e. chitosan or chitin [1-3]. Using solid waste suitable for pretreatment of wastewater containing petroleum hydrocarbons can solve two 
problems, one related to the presence of large amounts of waste that can be recycled in pretreatment/treatment processes of wastewater and another problem to reduce costs on their treatment [4-8].

\section{Materials and Methods}

In the study, wastewaters from petroleum oil extraction unit were collected. Wastewater was collected after the gravitational separation stage. Wastewater is treated by coagulation processes. The coagulation was performed with a stirrer with variable speeds (Phipps \& Bird Company USA). The coagulant was poly-aluminum chloride (PAC), $\mathrm{OH} / \mathrm{Al}=2.4$ molar ratio. The optimal dose (OD) of PAC coagulant in the absence /presence of chitosan was assessed by Jar Test method. The wastewater used for treatment was in volumes of $250 \mathrm{ml}$, in adequate vessels. Working conditions were: slow stirring for 15 minutes and gravitational sedimentation for 30 minutes. In the supernatant, were analyzed the following conventional parameters: $\mathrm{pH}$ using $\mathrm{pH}$ - meter model 290A ORION RESEARCH USA, turbidity with Micro 100 Laboratory Turbid meter, Scientific Inc. USA, COD by hot $\mathrm{K}$ dichromate oxidation in strongly acidic medium, TOC using TOC Analyzer Multi N/C2100 Analytic Jena, Germany, TPH were determined according to the Romanian norms, by extraction with solvent (SR 7877/2-95). The nonconventional parameter, the absorbance at $254 \mathrm{~nm}$ wave length (A245), was quickly analyzed by UVVIS spectrophotometer, Specord 205, Analytik Jena, Germany. Treated water samples must have the characteristics required by national norm HG 352/2005-NTPA 002 to be discharged into the sewerage networks of localities and directly in wastewater treatment plants: $\mathrm{pH}=6.5-8.5, \mathrm{~m}$ maximum $\mathrm{COD}=500 \mathrm{mgO}_{2} \cdot \mathrm{L}^{-1}$, maximum $\mathrm{TPH}=5 \mathrm{mg} \cdot \mathrm{L}^{-1}[9]$.

\section{Results and Discussion}

In Table 1 are shown the conventional parameters i.e.: $\mathrm{pH}$, turbidity, COD, TOC, TPH and the nonconventional parameter - absorbance at $\lambda=254 \mathrm{~nm}$, A254 of the wastewater. The water sample contained TPH with $48-64 \%$ more than the admissible Romanian values to be discharged into the sewerage networks of localities and directly in wastewater treatment plants. The absorbance, A254, was in the range of $2.30 \pm 0.08$ a.u. (absorbance unit)

Table $1 \mathrm{TPH}$ wastewater characterization

\begin{tabular}{|l|l|l|l|l|l|l|}
\hline Wastewater & \multicolumn{6}{|c|}{ Parameters } \\
\cline { 2 - 7 } & $\mathrm{pH}$ & $\begin{array}{l}\text { Turbidity } \\
{\left[{ }^{0} \mathrm{NTU}\right]}\end{array}$ & $\begin{array}{l}\mathrm{COD} \\
{\left[\mathrm{mgO}_{2} \cdot \mathrm{L}^{-1}\right]}\end{array}$ & $\begin{array}{l}\mathrm{TPH} \\
{\left[\mathrm{mg} \cdot \mathrm{L}^{-1}\right]}\end{array}$ & $\begin{array}{l}\mathrm{TOC} \\
{\left[\mathrm{mgC} \cdot \mathrm{L}^{-1}\right]}\end{array}$ & $\begin{array}{l}\mathrm{A} 254 \\
{\left[\mathrm{Cm}^{-1}\right]}\end{array}$ \\
\hline 1 & 8.2 & $65.2 \pm 12.6$ & $376.5 \pm 120.3$ & $270.6 \pm 32.4$ & $101.30 \pm 12.8$ & $2.30 \pm 0.08$ \\
\hline
\end{tabular}

1. PAC wastewaters coagulation.

Table 2 shows the characteristics of the samples treated with the optimal dose of PAC and process efficiencies. Optimal dose was established by Jar-Test Method. From Table 2 we see that the reduction efficiencies of TPH and TOC values are similar to A254 value reduction for the optimal dose. 
Table 2. Treated water samples with PAC optimal dose and coagulation process efficiencies (PAC optimal dose $=16 \mathrm{mg} \cdot \mathrm{L}^{-1}$ )

\begin{tabular}{|c|c|c|c|}
\hline No & Parameters & Treated water samples & Efficiencies [\%] \\
\hline 1 & Turbidity $\left[{ }^{\circ} \mathrm{NTU}\right]$ & 12.5 & 80.7 \\
\hline 2 & $\mathrm{COD}\left[\mathrm{mgO} \cdot \mathrm{L}^{-1}\right]$ & 393 & - \\
\hline 3 & $\mathrm{TPH}\left[\mathrm{mg} \cdot \mathrm{L}^{-1}\right]$ & 59.7 & 77.9 \\
\hline 4 & $\mathrm{TOC}\left[\mathrm{mgC} \cdot \mathrm{L}^{-1}\right]$ & 37.2 & 63.1 \\
\hline 5 & $\mathrm{~A} 254\left[\mathrm{~cm}^{-1}\right]$ & 0.8 & 65.2 \\
\hline
\end{tabular}

In Figure 1 we see that the optimal dose of coagulation agent can be determined in conjunction with the varying spectra of water treated with different doses of coagulating agent. Optimal dose for wastewater coagulation process for was $16\left[\mathrm{mgAl} \cdot \mathrm{L}^{-1}\right]$. A254 reduction was up to $65.2 \%$ for optimal dose of PAC. Although there have been obtained high efficiencies of the coagulation process, the treated water sample contained TPH with 10 times more than the admissible Romanian norm HG 352/2005-NTPA 002.

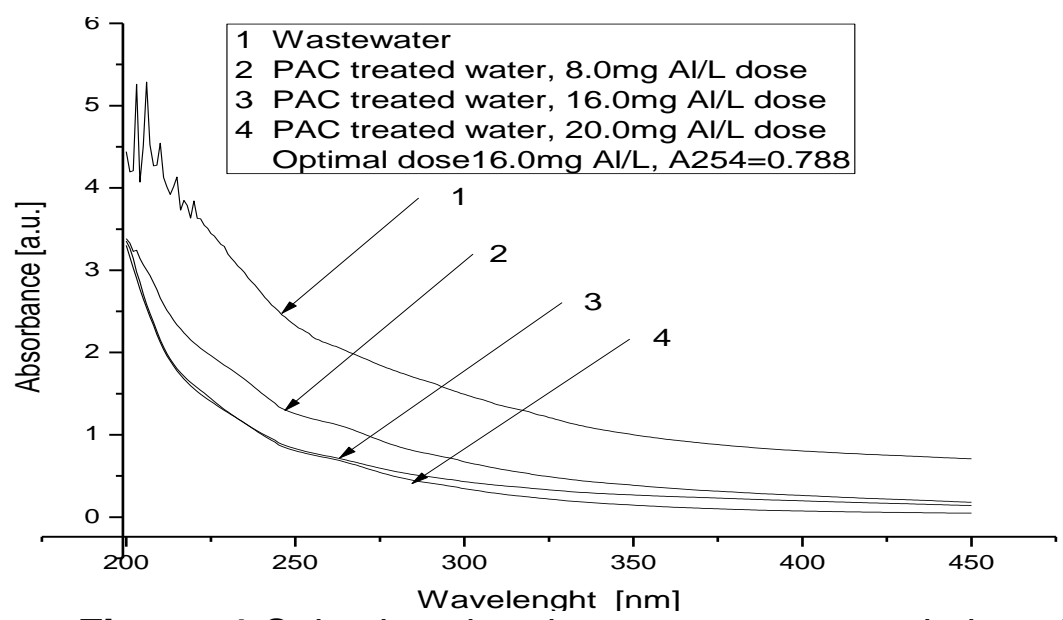

Figure. 1 Selective absorbance spectrum evolution after Jar test application to establish the optimal dose for wastewater treatment with PAC coagulation agents

2. Chitosan: Al wastewaters coagulation.

In Table 3 are presented the characteristics of treated water obtained by coagulating with Chitosan: Al and coagulation process efficiencies.

Table 3 Treated water samples with Chitosan: Al optimal dose (OD) and coagulation process efficiencies

\begin{tabular}{|c|c|c|c|c|c|}
\hline \multirow[t]{3}{*}{ No } & \multirow[t]{3}{*}{ Parameters } & \multicolumn{4}{|c|}{ Coagulant type } \\
\hline & & \multicolumn{2}{|c|}{$\begin{array}{c}\text { Chitosan :Al } 0.3 \text { ratio OD } \\
1=10.0 \mathrm{mg} \mathrm{Al} \cdot \mathrm{L}^{-1}\end{array}$} & \multicolumn{2}{|c|}{$\begin{array}{l}\text { Chitosan :Al } 0.6 \text { ratio, } \\
\text { OD } 2=7.6 \mathrm{mg} \mathrm{Al} \cdot \mathrm{L}^{-1}\end{array}$} \\
\hline & & Values & $\begin{array}{c}\text { Efficiencies } \\
{[\%]}\end{array}$ & Values & $\begin{array}{c}\text { Efficiencies } \\
{[\%]}\end{array}$ \\
\hline 1 & Turbidity $\left[{ }^{\circ} \mathrm{NTU}\right]$ & 11.5 & 82.3 & 12.5 & 80.7 \\
\hline 2 & $\mathrm{COD}\left[\mathrm{mgO}_{2} \cdot \mathrm{L}^{-1}\right]$ & 326.3 & 13.2 & 327.5 & 12.9 \\
\hline 3 & $\mathrm{TPH}\left[\mathrm{mg} \cdot \mathrm{L}^{-1}\right]$ & 41.6 & 84.6 & 22.0 & 91.8 \\
\hline 4 & TOC $\left[\mathrm{mgC} \cdot \mathrm{L}^{-1}\right]$ & 30.9 & 69.4 & 25.1 & 75.4 \\
\hline 5 & $\mathrm{~A} 254\left[\mathrm{~cm}^{-1}\right]$ & 0.915 & 60.2 & 0.63 & 72.6 \\
\hline
\end{tabular}


In figures 2 are shown two selective absorbance spectra evolution after Jar test application to establish the optimal dose for coagulation wastewater with coagulation agents chitosan: Al 0.3 ratio, and chitosan:Al 0.6 ratio.

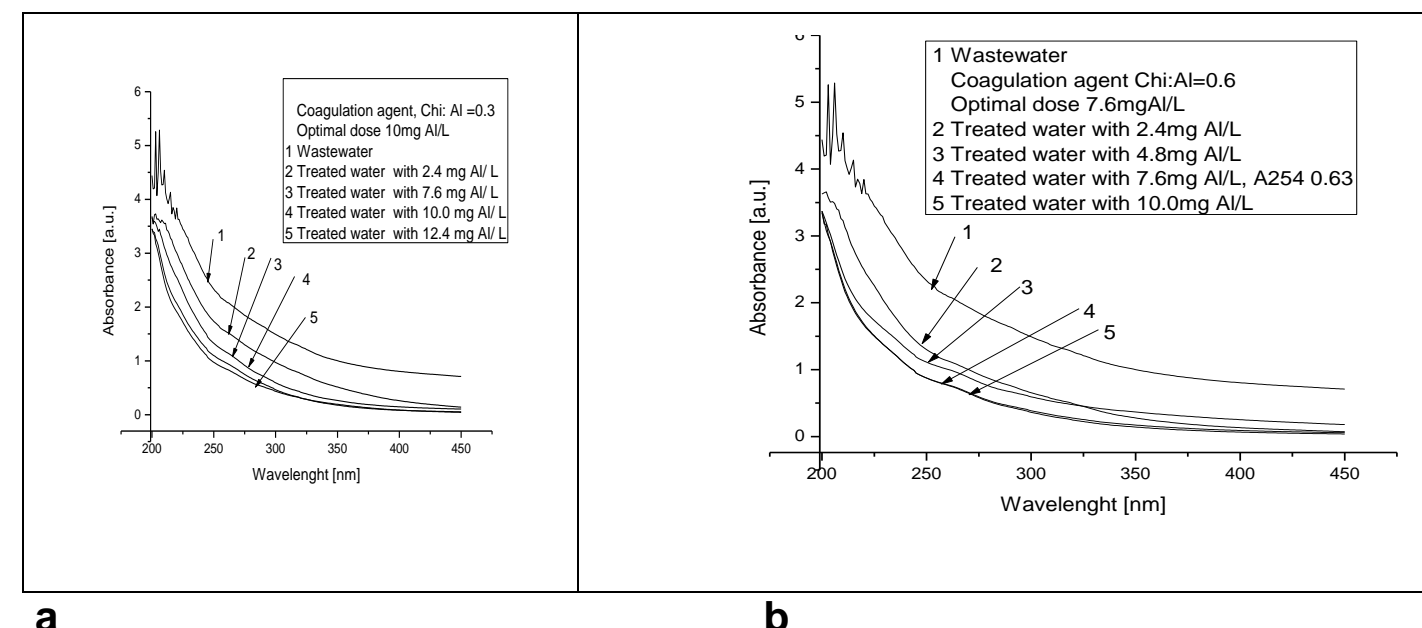

Fig. 2 Selective absorbance spectrum evolution after Jar test application to establish the optimal dose for wastewater treatment with coagulation agents a) Chitosan: $\mathrm{Al}=0.3$ ratio, b) Chitosan: $\mathrm{Al}=0.6$ ratio

In Figure $2 a$ and Figure $2 b$ is seen that the optimal dose of the coagulation agent chitosan: Al can be determined in conjunction with the varying spectra of water treated with different doses of coagulating agent. If using chitosan: $\mathrm{Al}=$ 0.3 ratio as coagulant agent, the dose of $\mathrm{Al}$ is reduced with $37.5 \%$. When using chitosan: $\mathrm{Al}=0.6$ ratio, as coagulant agent, the dose of $\mathrm{Al}$ is reduced by $52.5 \%$. $\mathrm{TPH}$ reduction efficiency when using coagulation agent chitosan: $\mathrm{Al}=0.6$ ratio, increases from $77.9 \%$ - efficiency obtained when using PAC in the absence of chitosan - to $91.8 \%$ in chitosan presence- (see figure 2)

\section{Conclusions}

To improve the efficiency of the process of coagulation of wastewaters with high content of petroleum products, TPH, coagulating agents were used based on poly-aluminum chloride and materials obtained from shell and fish waste recycling, i.e. chitosan. The efficiency was assessed by conventional parameters: turbidity, COD, TOC, $\mathrm{pH}, \mathrm{TPH}$, and unconventional parameter, absorbance at $254 \mathrm{~nm}$ wavelength, A254. The use of mixed coagulating agent chitosan: Al of 0.3 and 0.6 ratios respectively determined the reduction of PAC coagulant respectively the Al dose. In addition, high process efficiencies were obtained. Coagulation performance obtained with the coagulant chitosan: Al was reported to the results of the PAC coagulation in the absence of chitosan. The results show that using the mixed agent chitosan: $\mathrm{Al}=0.6$ ratio determined efficiencies of reduction of the optimal dose of PAC up to $52.5 \%$ and obtaining treated samples with top characteristics to the samples treated with optimal doses PAC. The correlation of the values of the conventional parameters of untreated/treated water with the unconventional parameter absorbance at 
wavelength 254, may allow the introduction of the A254 parameters, , in rapidly raw and treated water characterization monitoring and determining the efficiencies of the coagulation stage.

\section{Acknowledgements}

The research given the Ministry of Education Research, Youth and Sports which provide financial support for Nucleu Program PN 09-13 03 22. Thank are due to: Mariana Albulescu West University of Timisoara, Advanced Environmental Research Laboratories, Romania.

\section{References}

1. Ng M., Liana A. E., Liu S., Lim M., Chow C. W. K., Wang D., Drukas M., Amal R., (2012), Preparation and characterization of new-polyaluminum chloride-chitosan composite coagulant, Water Research, 46, 4614-4620.

2. Renault F., Sansei B., Bardot P.M., Crain G., (2009). Chitosan for coagulation/flocculation processes - An eco-friendly approach, European Polymer Journal, 45, 1337-1348..

3. Ahmad A. L., Samadhi S., Hammed B. H., (2005). Residual oil and suspended solid removal using natural adsorbents chitosan, bentonite and activated carbon: A comparative study, Chemical Engineering Journal, 108, 179-185.

4. Masu S., (2013), Removal of Dissolved Organic Carbon by Processes of Coagulation, Journal of Environmental Protection and. Ecology, 14 (1), 49-54.

5. Kumanova B., Jitaru M., (2007), Adsorption on natural material from Balkan area alternative methods applied for the environmental protection, Journal of Environmental Protection and Ecology, 8 (1), 35-40.

6. Cojocaru C., Cretu V. C., Preda C., Macoveanu M., Cretescu I. (2010), Response surface methodology applied for investigation of diesel oil spill removal from water surface using textile sorbents. Journal of Environmental Protection and. Ecology, 11 (2), 643-648.

7. Mamoukars A., Mimis S., Karakolios E., Xipolitos K., Patsioura G., (2014), New Friendly to Environment Method in Wastewater Treatment, Journal of Environmental Protection and. Ecology, 15 (3), 1021-1026.

8. Cojocaru C.., Cretescu J., Sorbeanu G., Popa C., Macoveanu M., (2006), Applying of peat as floating sorbent in order to remove diesel spill from wastewater surface process optimization, Journal of Environmental Protection and. Ecology ,7 (2), 397-402

9. HG 352/2005 NTPA 002 , (2005).Amending and supplementing Government Decision no 188/2002 to approving the rules on the condition of discharging wastewater into the aquatic environment, Romania, Monitor Official, Bucuresti, 378 